\title{
DIVERSIDADE E GÊNERO NO CONTEXTO ORGANIZACIONAL: UM ESTUDO BIBLIOMÉTRICO
}

\section{DIVERSITY AND GENDER IN THE ORGANIZATIONAL CONTEXT: A BIBLIOMETRIC STUDY}

\author{
Recebido em 14.04.2015. Aprovado em 02.09.2015 \\ Avaliado pelo sistema double blind review
}

João Batista Ferreira

coordenacaoadmfcc@hotmail.com

Universidade Federal de Goiás, Goiânia/GO, BRASIL

\author{
Adriana Santos Prado Sadoyama \\ drisadoyama@gmail.com \\ Universidade Federal de Goiás, Goiânia/GO, BRASIL
}

\author{
Aline Ferreira Campos Correia \\ aline.farma.bio@hotmail.com \\ Universidade Federal de Goiás, Goiânia/GO, BRASIL
}

\section{Pietro Aguiar T. de P. Gomes}

coordenacaoadmfcc@hotmail.com

Universidade Federal de Goiás, Goiânia/GO, BRASIL

\begin{abstract}
Resumo
Este artigo explora o acervo dos periódicos da Associação Nacional de Pós Graduação em Administração (ANPAD), especificamente no evento Encontro Nacional de Estudos Organizações (EnEO), relacionados com o tema gênero e diversidade, por meio do uso de técnicas bibliométricas. O presente estudo tem como objetivo fundamental aprofundarse nas temáticas: gênero e diversidade, através de análises das principais características das publicações sobre este tema. A metodologia utilizada foi à pesquisa descritiva, quanto a abordagem quantitativa e quanto aos procedimentos revisão bibliográfica. Os resultados encontrados demostraram a diversidade de estudos recentes que tratam dos temas em questão. Percebe-se que os estudos relacionados às pessoas nas organizações, como diversidade, gênero, entre outros, em comparação com as práticas organizacionais, demonstram que os estudos ainda não passam de ilusão e sentimentalismo, sendo que a realidade organizacional é bem diferente, a visão capitalista prevalece. Ainda bem que esta realidade empresarial lentamente está mudando, compreendendo que a diversidade na organização é algo que contribui para o crescimento e desenvolvimento das mesmas. Através desta diferenciação, com visões e entendimentos diferenciados, as organizações podem conseguir atingir melhor seus objetivos organizacionais na ótica de produção, do que em um ambiente homogêneo. E independente de conseguirem vantagens competitivas, compreender a diversidade organizacional é algo primordial, pois as empresas vivem em um ambiente de diversidades.
\end{abstract}

Palavras-chave: Sexualidade. Raça. Discriminação.

\section{Abstract}

This article explores the collection of periodicals of the National Association of Graduate in Administration (ANPAD), specifically in the event National Organizations Studies Meeting (EnEO) relating to the theme of gender and diversity, through the use of bibliometric techniques. This study has as its fundamental objective to deepen the themes: gender and diversity through analysis of the main characteristics of publications on this theme. The methodology used was the descriptive research on the quantitative approach and about the literature review procedures. The results demonstrated the diversity of recent studies dealing with the issues in question. It is noticed that the studies related to people in organizations, such as diversity, gender, among others, in comparison with the organizational practices, demonstrate that the studies still are but illusion and sentimentality, and the organizational reality is quite different, vision capitalist prevails. Good thing this is business reality slowly changing, realizing that diversity in the organization is something that contributes to the growth and development of the same. Through this differentiation, with different views and understandings, organizations can get better achieve their organizational goals in optical production, than in a homogeneous environment. And independent of achieving competitive advantages, understand the organizational diversity is something primordial, as companies live in a diversity environment.

Keywords: Sexuality. Race. Discrimination. 


\section{Introdução}

Os trabalhos acadêmicos no Brasil são escassos sobre diversidade e gênero, e é um assunto novo para os estudos organizacionais. Andrade, Macedo e oliveira (2014) relata que os trabalhos analisando a produção científica brasileira em gênero, diversidades e minorias, e masculinidades, especificamente na área de estudos organizacionais, foram realizados por (COSTA, FERREIRA, 2006; CAPELLE, et. al., 2007; SOUZA, et. al., 2012; SOUZA, CORVINE e LOPES, 2013) e nos revelam uma aumento no número de publicações sobre a temática, evidenciando que o campo ainda esta em construção.

A fim de ampliar o conhecimento e discussão sobre os temas em questão, este trabalho tem como objetivo fundamental aprofundar-se nas temáticas: gênero e diversidade, através de análises das principais características das publicações sobre estes assuntos. Propõe-se através do uso da bibliometria enquanto instrumento de mensuração da produção cientifica e acadêmica, analisar os vieses gênero, raça e etnia, sexualidade, idade, pessoas com necessidade especiais, dentre outros no contexto organizacional.

Este artigo é estruturado em cinco (5) sessões distintas, incluindo a introdução, na sessão dois (2) a fundamentação teórica, diversidade, contextualizando gênero, sexualidade: diversidade, discriminação e preconceitos, relações étnico-raciais; na sessão três (3) apresentaremos os métodos; e na sessão quatro (4) os resultados; e em sequência a conclusão e referências.

\section{Fundamentação teórica}

\section{Diversidade}

O aspecto sobre diversidade nas organizações vem sendo discutido por vários autores, abordando sobre vários assuntos, com destaque, a presença dos afrodescendentes, dos portadores de necessidades especiais, das mulheres e das pessoas com diferentes orientações sexuais, no contexto dos estudos administrativos brasileiros (COSTA, FERREIRA, 2006).

Quanto à diversidade no mercado de trabalho, Hanashiro, Godoy e Carvalho (2004) enfatizam a escassez de produção acadêmica sobre o assunto, e demonstram um foco estreito da diversidade, com ênfase em gênero e portadores de necessidades especiais; Rezende e Carvalho-Freitas (2014) descrevem as atitudes dos profissionais de recursos humanos frente à inclusão de pessoas com deficiência no mercado de trabalho.

Já Vieira Junior, Lima, Lima (2014) preocupou-se em observar e identificar o processo de socialização das pessoas com deficiências nas organizações; por outro lado Siqueira e Prelorentzou (2008) destacam a violência moral no ambiente organizacional envolvendo as pessoas com deficiências e os homossexuais; e a qualificação profissional dos trabalhadores com deficiência (LIMA, 2014).

Irigaray (2010) aborda a inserção dos travestis e transexuais no mundo do trabalho e os preconceitos e discriminações sofridas pelos mesmos; Siqueira e Zauli-Fellows (2006) objetivou compreender as questões de identidade e culturas gay, no intuito de melhoria nas condições de trabalho.

Irigaray e Vergara (2008) relatam a convivência e o confronto de indivíduos de diferentes culturas nas organizações, através de um estudo dos expatriados no Brasil.

Tendo em vista a preocupação social das organizações, Rocha, Lima, Ferraz, Ferraz (2012) enfatizam a integração produtiva dos egressos de sistemas prisionais pelos profissionais de recursos humanos.

Nas várias citações supracitadas evidenciam a ênfase nos estudos sobre diversidade nas organizações.

\section{Contextualizando Gênero}

A compreensão das questões de gênero, masculinidade, diversidades e minorias no ambiente organizacional, tornam-se prioritária para as organizações, pois ao realizarem uma política inclusiva e respeito das diversidades no contexto organizacional, elas podem sair fortalecidas e contribuir para o amadurecimento dos debates internos e seus limites (ANDRADE, MACÊDO, OLIVEIRA, 2014).

A questão de gênero toca as nações de masculinidade e feminilidade, o que é ser masculino e feminino, como educar e ser educado, e construir uma identidade produzida pela cultura e sociedade, impregnada de atributos, privilégios e limitações, com explicações para as diferenças baseadas em características biológicas. As relações de gênero produzem uma distribuição desigual de poder, autoridade e prestigio entre as pessoas de acordo com o seu sexo (MACÊDO, MACÊDO, 2004). 
A maioria dos trabalhos abordam a inserção das mulheres no mercado de trabalho e suas características, apontando as características empreendedoras das mulheres e as relações trabalho-família.

Sabe-se que desde o inicio da civilização a mulher era vista como um ser inferior ao homem, sem poder de decisão e cujas principais funções era de reproduzir e criar os filhos. Durante séculos lutaram e foram em busca de seus direitos para se tornar independente e dona de suas próprias escolhas (FERREIRA, RESENDE, 2010).

Ferraz, Mapurunga, Ferraz (2012) enfatiza a inserção tardia das mulheres no mercado trabalho e a conjugação entre atividades profissionais bem sucedidas com missão familiar cumprida; Nassif, Andreassi, Tonelli (2014) abordam que para as empreendedoras brasileiras, os aspectos pessoais confundem-se com os profissionais.

A preocupação das mulheres sobre as relações trabalhofamília devem-se ao fato de que ainda prevalecem nos dias atuais as responsabilidades familiares recaindo apenas nas mulheres, com a omissão masculina.

As pesquisas revelam ainda a existência da dominação masculina nos campos profissional e pessoal (SOAREZ, MORAIS, SOUZA, 2012); enfatizando o homem como sexo forte (MEDEIROS, SILVA, 2014); e a distinção de atividades específicas para cada sexo, como nos trabalhos de Matos, Figueiredo, Quezado e Mesquita (2014) que evidenciaram os preconceitos masculinos em relação à costura enquanto atividade tradicionalmente feminina.

A mulher precisa reconhecer que é vitima da dominação masculina e assumir o controle de sua vida. Assim o empoderamento da mulher é um fator fundamental para o desenvolvimento da sociedade (FELIPE, MELO, PINTO, LOPES, 2014).

\section{Sexualidade: diversidade, discriminação preconceitos}

A diversidade inclui raça, gênero, idade, estilo de vida, preferência sexual, etc. (SILVA, ALVES, 2002). Porém vivemos em um mundo onde a preferência sexual, ainda é vista de maneira discriminada e preconceituosa, todavia através de lutas e questionamentos esta visão esta sendo mudada.

Quanto aos homossexuais, quantos não transitam invisíveis e divididos num mundo organizacional cercado de preconceitos? (COSTA, FERREIRA, 2006).

Siqueira, Zauli-Fellows (2006) relatam que um dos grupos mais marginalizados nas organizações é o dos gays e das lésbicas, porque muitas vezes eles são obrigados a não revelarem suas identidades. As empresas se deparam cada vez mais com a questão de empregados gays e lésbicas, sendo necessário o desenvolvimento de políticas que sejam interessantes para seus empregados e organização.

Para os gestores organizacionais, as pessoas são o que há de mais importante nas organizações. Assim valorizar a diversidade, e principalmente manter um ambiente harmonioso é papel fundamental.

A miséria e a violência experimentadas, no Brasil, pelos travestis e transexuais são decisivos para decidir seus destinos: a grande maioria se prostitui, no mercado de trabalho exercem funções operacionais, a maioria tem baixa educação formal. Por este motivo, as travestis, transexuais, devem ser incorporados na agencia de discussão sobre diversidade nas organizações, bem como estabelecer politicas organizacionais garantindo um mundo habitável e acolhedor para os mesmos (IRIGARAY, 2010).

\section{Relações Étnico-raciais}

O racismo no Brasil não é um fato admitido com facilidade, por detrás do mito da democracia racial esta o negro vivendo as margens da sociedade, excluídos das atividades rentáveis, barreiras encontradas nos processos seletivos de empresas privadas. Assim, mesmos os negro bem preparados em termos de formação acadêmica e profissional tem dificuldades de acesso às melhores posições (COSTA, FERREIRA, 2006).

Evidencia-se resistência na discussão sobre raça nos estudos organizacionais. Assunto abordado de maneira sucinta, citando a importância das observações dos aspectos raciais na discussão sobre diversidade.

Somente o trabalho de Costa e Ferreira (2006) que discorreu este assunto com maior clareza, e enfatizando também que os negros não estão, em sua maioria entre os vencedores, não podem escrever sobre suas histórias de sucesso e glória nas organizações, e que a realidade de pesquisas que abordam a realidade dos negros nas organizações é imperiosa, e elogiam 
os Congressos de Pesquisadores Negros que tentam dar visibilidade aos trabalhos existentes sobre este assunto.

E Rosa, Alves (2014) que abordou o processo de racialização no Brasil, citando as principais políticas implementadas e o combate ao racismo.

Além de discutir sobre o tema étnico-racial, precisamos reforçar a necessidade de abrir os olhos frente aos preconceitos e discriminação existentes nos dias atuais, e fazer valer os direitos de todos, bem como aprofundar na temática de inclusão dos negros no mercado de trabalho.

\section{Métodos}

Para a construção deste estudo foi utilizado às técnicas de bibliometria que possibilita o mapeamento de pesquisa, explorando o acervo de periódicos da Associação Nacional de Pós-Graduação e Pesquisa em Administração - ANPAD, exclusivamente no Encontro Nacional de Estudos Organizacionais (EnEO).

Francisco (2011) ressalta que a bibliometria trata-se de técnicas quantitativas de analisar produções científicas, cujo objetivo principal é analisar a produção cientifica relacionado com o tema proposto, disseminação e uso de informações registradas com o emprego de métodos matemáticos e estatísticos.

Analisam-se o conteúdo, envolvendo títulos, palavraschave, resumos, textos, autores, instituições, métodos, envolvendo autoria e referências bibliográficas (FERREIRA, SADOYAMA, 2015). Observando as principais características gerais das publicações: ano de publicação, evento ou periódicos, principais autores, número de autores por artigo, instituições, e também aspectos metodológicos das publicações: Quanto aos objetivos da pesquisa, abordagem, procedimentos, instrumentos utilizados para a coleta de dados, dentre outros.

Quantoá abordagem está pesquisa pode ser classificada como pesquisa quantitativa, pois utilizaremos métodos estatísticos na coleta e analise dos dados. Para Mattar, (2001), a pesquisa quantitativa busca a validação das hipóteses mediante a utilização de dados estruturados, estatísticos, com análise de um grande número de casos representativos.
Quanto aos objetivos classifica-se como pesquisa descritiva, pois buscaremos investigar uma serie de informações relacionadas ao assunto da pesquisa. A pesquisa descritiva identifica as características da produção cientifica atual sobre o tema, de determinados fenômenos ou população (TROCCOLI et. al., 2011). E relacionado aos procedimentos é uma pesquisa bibliográfica, sendo que a bibliometria tem como objetivo o levantamento de referências teóricas já utilizadas.

A coleta de dados abrangeu amostras relevantes relacionadas ao tema de estudo, selecionados e apresentados nos periódicos ANPAD, referente aos eventos do EnEO da ANPAD. A escolha destes eventos como base de pesquisa é devido à importância e relevância nos campos de pesquisa, pois o EnEO tem a finalidade de fomentar o desenvolvimento da área de estudos em organizacionais no Brasil, por meio de estudos teórico e/ou teórico empíricos considerando os diferentes subsistemas e dimensões de análise, sendo órgão de referencia no papel de disseminação de conhecimentos científicos e acadêmicos.

Delimitou-se como unidades de analise os periódicos já citados, no EnEO da ANPAD, no período de 2000 à 2014, todos os assuntos relacionados ao tema diversidade e gênero, foram levantadas as produções acadêmicas a serem analisadas, sendo que deste universo foram extraídas quarenta e seis (46) publicações no total, considerando aspectos de maior relevância para o assunto proposto.

Para a análise dos dados foi montado um banco de dados no Microsoft Office Excel 2010, contendo as seguintes características de todas as publicações: título, nome dos autores, formação dos autores, quantidade de autores por publicação, ano de publicação, temas de interesses, instituições vinculadas pelos autores, objetivos da pesquisa, considerações finais e conclusões, e também aspectos metodológicos das publicações. Em sequência os dados coletados foram tratados através de formulas estatísticas, a fim de detectar o percentual necessário de cada item analisado, servindo de suporte para identificar os resultados esperados, e auxiliar nas conclusões finais. 


\section{Resultados}

Dentre os principais estudos organizacionais, no EnEO da ANPAD com ênfase na diversidade e gênero, entre o período de 2000 à 2014, foram selecionados 46 publicações no total.

O quadro 1 apresenta as pesquisas com ênfase na diversidade, e o quadro 2 apresenta as pesquisas com ênfase no gênero abordando os autores, objetivo geral e as considerações/conclusões.

Quadro 1 . Pesquisas com ênfase nas questões de diversidade, no EnEO, no período de 2000 - 2014.

\begin{tabular}{|c|c|c|c|c|}
\hline AUTOR (ES) & OBJETIVOS & METODOLOGIA & $\begin{array}{l}\text { CONSIDERAÇÕES/ } \\
\text { CONCLUSÃO }\end{array}$ & \\
\hline SILVA, ALVES (2002) & $\begin{array}{l}\text { Analisar a ideologia da } \\
\text { diversidade. }\end{array}$ & $\begin{array}{l}\text { Descritiva, qualitativa e } \\
\text { Revisão bibliográfica. }\end{array}$ & $\begin{array}{l}\text { Nas organizações a } \\
\text { diversidade é uma } \\
\text { falsa novidade. Ela } \\
\text { não muda o valor } \\
\text { das pessoas, pois } \\
\text { estas continuam a ser } \\
\text { consideradas sob a } \\
\text { ótica da produção. }\end{array}$ & \\
\hline $\begin{array}{l}\text { HANASHIRO, GODOY, } \\
\text { CARVALHO (2004) }\end{array}$ & $\begin{array}{l}\text { Promover a reflexão } \\
\text { sobre o conceito de } \\
\text { diversidade cultural, do } \\
\text { ponto de vista teórico } \\
\text { á luz e experiências } \\
\text { brasileiras. }\end{array}$ & $\begin{array}{l}\text { Descritiva, qualitativa, } \\
\text { estudo de caso, foi } \\
\text { utilizado à entrevista } \\
\text { para a coleta de dados. }\end{array}$ & $\begin{array}{l}\text { Os resultados } \\
\text { revelaram um foco } \\
\text { estreito de diversidade, } \\
\text { com ênfase no gênero } \\
\text { e portadores de } \\
\text { necessidades especiais. }\end{array}$ & \\
\hline MENDES (2004) & $\begin{array}{l}\text { Olhar crítico sobre as } \\
\text { referências atualmente } \\
\text { feitas à diversidade } \\
\text { cultural como fonte de } \\
\text { vantagem competitiva } \\
\text { empresarial. }\end{array}$ & $\begin{array}{l}\text { Descritiva, qualitativa e } \\
\text { Revisão bibliográfica. }\end{array}$ & $\begin{array}{l}\text { Além da analise do } \\
\text { balanço entre prós e } \\
\text { contra da diversidade, } \\
\text { este artigo ressaltou } \\
\text { a importância dos } \\
\text { assuntos relacionados à } \\
\text { promoção de justiça e } \\
\text { bem-estar social. }\end{array}$ & \\
\hline COSTA, FERREIRA (2006) & $\begin{array}{l}\text { Mapear a presença } \\
\text { dos afro-decendentes, } \\
\text { dos portadores de } \\
\text { necessidades especiais, } \\
\text { das mulheres e das } \\
\text { pessoas com diferentes } \\
\text { orientações sexuais } \\
\text { no contexto dos } \\
\text { estudos administrativos } \\
\text { brasileiros. }\end{array}$ & $\begin{array}{l}\text { Descritiva e } \\
\text { exploratória, qualitativa } \\
\text { e Revisão. bibliográfica. }\end{array}$ & $\begin{array}{l}\text { Os temas que } \\
\text { permanecem } \\
\text { praticamente } \\
\text { inexplorados nos } \\
\text { estudos organizacionais } \\
\text { são os de raça e } \\
\text { de etnia e inclusão } \\
\text { de pessoas com } \\
\text { orientações sexuais } \\
\text { diversas. }\end{array}$ & \\
\hline $\begin{array}{l}\text { SIQUEIRA, FELOWS } \\
(2006)\end{array}$ & $\begin{array}{l}\text { O estudo analisa a } \\
\text { diversidade cultural } \\
\text { nas organizações e, em } \\
\text { especial a orientação } \\
\text { sexual. }\end{array}$ & $\begin{array}{l}\text { Descritiva, qualitativa e } \\
\text { Revisão bibliográfica. }\end{array}$ & \multicolumn{2}{|c|}{$\begin{array}{l}\text { As empresas se deparam cada vez mais com } \\
\text { a questão de empregados gays e lésbicas, } \\
\text { sendo necessário o desenvolvimento de } \\
\text { políticas que sejam de interesses para seus } \\
\text { empregados e organização. }\end{array}$} \\
\hline
\end{tabular}




\begin{tabular}{|c|c|c|c|}
\hline DOVAL, HARO (2006) & $\begin{array}{l}\text { Mostrar como a } \\
\text { ação do capital sobre } \\
\text { uma organização } \\
\text { social pode ter um } \\
\text { caráter excludente, } \\
\text { exploratório, e } \\
\text { consequentemente } \\
\text { ingênuo à luz de } \\
\text { Guerreiro Ramos } \\
\text { (1983). }\end{array}$ & $\begin{array}{l}\text { Descritiva, qualitativa, } \\
\text { estudo de caso e } \\
\text { documental, foi } \\
\text { utilizado a analise } \\
\text { documental e } \\
\text { entrevista para a coleta } \\
\text { de dados. }\end{array}$ & $\begin{array}{l}\text { Ao final fica evidente que as práticas } \\
\text { ingênuas das organizações capitalistas } \\
\text { atuam no sentido de absorver as inovações } \\
\text { sociais propostas por este projeto, impondo } \\
\text { desta forma barreiras à inclusão das pessoas } \\
\text { portadoras de deficiência no mercado de } \\
\text { trabalho. }\end{array}$ \\
\hline $\begin{array}{l}\text { IRIGARAY, VERGARA } \\
(2008)\end{array}$ & $\begin{array}{l}\text { Determinar se as } \\
\text { percepções dos } \\
\text { expatriados que vivem } \\
\text { no Brasil diferem } \\
\text { em função de sua } \\
\text { nacionalidade. }\end{array}$ & $\begin{array}{l}\text { Descritiva, qualitativa, } \\
\text { pesquisa de campo, foi } \\
\text { utilizado à entrevista e } \\
\text { observação para coleta } \\
\text { de dados. }\end{array}$ & $\begin{array}{l}\text { Os brasileiros são percebidos pelos } \\
\text { expatriados, como pessoas que conversam, } \\
\text { sorriem, valorizam diferentemente os } \\
\text { expatriados pertencentes a diferentes } \\
\text { culturas, ou seja, brasileiros são } \\
\text { hospitaleiros com expatriados. }\end{array}$ \\
\hline $\begin{array}{l}\text { SIQUEIRA, } \\
\text { PRELORENTZOU (2008) }\end{array}$ & $\begin{array}{l}\text { Analisar o fenômeno } \\
\text { da violência moral no } \\
\text { ambiente de trabalho } \\
\text { envolvendo pessoas } \\
\text { com deficiência. }\end{array}$ & $\begin{array}{l}\text { Descritiva, qualitativa, } \\
\text { pesquisa de campo, foi } \\
\text { utilizado de entrevista } \\
\text { para coleta de dados. }\end{array}$ & $\begin{array}{l}\text { Evidenciou-se que para as pessoas com } \\
\text { deficiência, a discriminação, e a falta de } \\
\text { apoio social são alguns dos principais } \\
\text { obstáculos para a inclusão efetiva no } \\
\text { mercado de trabalho, e não os limites do } \\
\text { corpo. }\end{array}$ \\
\hline IRIGARAY (2010) & $\begin{array}{l}\text { Visa estudar como } \\
\text { os indivíduos cuja } \\
\text { identidade sexual } \\
\text { não é hegemônica, } \\
\text { notadamente as } \\
\text { travestis e transexuais, } \\
\text { se insere no mundo do } \\
\text { trabalho. }\end{array}$ & $\begin{array}{l}\text { Descritiva, qualitativa, } \\
\text { pesquisa de campo, foi } \\
\text { utilizado à entrevista e } \\
\text { observação para coleta } \\
\text { de dados. }\end{array}$ & $\begin{array}{l}\text { A miséria e a violência experimentadas, no } \\
\text { Brasil, por estes indivíduos, levam a grande } \\
\text { maioria a se prostituir, e os que consegui } \\
\text { entrar no mercado de trabalho formal, } \\
\text { exercem funções operacionais, mesmo } \\
\text { assim são vitimas de agressões, violência } \\
\text { e intolerância por parte dos colegas de } \\
\text { trabalho. }\end{array}$ \\
\hline GASPAR et. al., (2012) & $\begin{array}{l}\text { Relatar a opinião das } \\
\text { pessoas quanto às } \\
\text { ações de qualidade } \\
\text { de vida no trabalho } \\
\text { promovida pelas } \\
\text { organizações. }\end{array}$ & $\begin{array}{l}\text { Descritiva, quantitativa, } \\
\text { estudo de caso, foi } \\
\text { utilizado o Protocolo } \\
\text { Padronizado - Medida } \\
\text { de Opinião para coleta } \\
\text { de dados. }\end{array}$ & $\begin{array}{l}\text { Mostram-se indícios de que o programa } \\
\text { de qualidade de vida no trabalho é viável } \\
\text { nas organizações e pode proporcionar } \\
\text { efetivamente a satisfação em pessoas } \\
\text { com deficiência sob o atual contexto da } \\
\text { diversidade. }\end{array}$ \\
\hline ROCHA et. al., (2012) & $\begin{array}{l}\text { Identificar como as } \\
\text { áreas de gestão de } \\
\text { pessoas, de empresas } \\
\text { participantes de } \\
\text { programas de } \\
\text { ressocialização de } \\
\text { egressos do sistema } \\
\text { prisional, se organizam } \\
\text { para obter a integração } \\
\text { produtiva desses } \\
\text { sujeitos. }\end{array}$ & $\begin{array}{l}\text { Descritiva, qualitativa, } \\
\text { estudo de caso } \\
\text { múltiplo, foi utilizado } \\
\text { a analise documental e } \\
\text { entrevista para coleta } \\
\text { de dados. }\end{array}$ & $\begin{array}{l}\text { Constata-se a incipiência das práticas } \\
\text { necessárias ao gerenciamento eficaz do } \\
\text { Programa de Ressocialização em todas as } \\
\text { empresas pesquisadas. }\end{array}$ \\
\hline
\end{tabular}




\begin{tabular}{|c|c|c|c|}
\hline LOTH, SILVEIRA (2012) & $\begin{array}{l}\text { Consiste em } \\
\text { uma investigação } \\
\text { sobre quais são os } \\
\text { esteriotipos percebidos } \\
\text { por profissionais } \\
\text { "envelhecentes" em } \\
\text { relação ao etarismo no } \\
\text { trabalho. }\end{array}$ & $\begin{array}{l}\text { Exploratória, } \\
\text { qualitativa, estudo de } \\
\text { caso, foi utilizado para } \\
\text { coleta de dados. }\end{array}$ & $\begin{array}{l}\text { A percepção dos envelhecentes frente } \\
\text { aos jovens revelou que os mesmos são } \\
\text { necessários para a continuidade de seu } \\
\text { cargo. Percebem no outro o papel de } \\
\text { substitutos; }\end{array}$ \\
\hline LIMA, LUCAS (2012) & $\begin{array}{l}\text { Discorrer sobre as } \\
\text { implicações à área de } \\
\text { RH no momento em } \\
\text { que estes assumem a } \\
\text { responsabilidade pela } \\
\text { gestão da diversidade } \\
\text { dentro do ambiente } \\
\text { organizacional. }\end{array}$ & $\begin{array}{l}\text { Descritiva, qualitativa e } \\
\text { Revisão bibliográfica. }\end{array}$ & $\begin{array}{l}\text { Constatou-se que a gestão da diversidade } \\
\text { surge como um tema emergente dentro } \\
\text { do ARH, apesar de pouco explorado no } \\
\text { contexto brasileiro, também pode ser } \\
\text { considerado como oportunidade de re- } \\
\text { conceituação dos seus papeis. }\end{array}$ \\
\hline $\begin{array}{l}\text { FERRAZ, } \\
\text { MAPURUNGA, } \\
\text { FERRAZ (2012) }\end{array}$ & $\begin{array}{l}\text { Analisar a inserção } \\
\text { tardia de mulheres no } \\
\text { mercado de trabalho. }\end{array}$ & $\begin{array}{l}\text { Descritiva, qualitativa, } \\
\text { estudo de caso } \\
\text { múltiplo, foi utilizado } \\
\text { à entrevista para coleta } \\
\text { de dados. }\end{array}$ & $\begin{array}{l}\text { Os resultados evidencia que a inserção } \\
\text { tardia mostra-se associado com sentimento } \\
\text { de inferioridade e de frustração por uma } \\
\text { suposta desvantagem aos sujeitos que não } \\
\text { se afastaram do mercado de trabalho por } \\
\text { tempo tão longo, realidade de redução } \\
\text { progressiva e oportunidades que se } \\
\text { relaciona com o avanço etário. }\end{array}$ \\
\hline $\begin{array}{l}\text { CARDOSO, HANASHIRO } \\
\text { (2012) }\end{array}$ & $\begin{array}{l}\text { Compreender } \\
\text { o processo de } \\
\text { Institucionalização } \\
\text { da Valorização } \\
\text { das iniciativas de } \\
\text { Diversidade no Campo } \\
\text { Organizacional. }\end{array}$ & $\begin{array}{l}\text { Descritiva, qualitativa, } \\
\text { estudo de caso, foi } \\
\text { utilizado à entrevista } \\
\text { para coleta de dados. }\end{array}$ & $\begin{array}{l}\text { Os resultados apontaram haver influencia } \\
\text { interorganizacional no processo de } \\
\text { compartilhamento e construção de } \\
\text { aprendizados sobre a valorização das } \\
\text { iniciativas de diversidade. }\end{array}$ \\
\hline $\begin{array}{l}\text { LIMA, VIEIRA JUNIOR, } \\
\text { LIMA (2014) }\end{array}$ & $\begin{array}{l}\text { Identificar as principais } \\
\text { características } \\
\text { do processo de } \\
\text { socialização das } \\
\text { pessoas com } \\
\text { deficiências (PCDs) } \\
\text { nas organizações. }\end{array}$ & $\begin{array}{l}\text { Descritiva, quantitativa, } \\
\text { estudo de caso, foi } \\
\text { utilizado o questionário } \\
\text { para coleta de dados. }\end{array}$ & $\begin{array}{l}\text { Os resultados indicam que esses } \\
\text { profissionais podem auxiliar a organização } \\
\text { na busca por inovações; apresentam um } \\
\text { bom nível de socialização; também aponta } \\
\text { a necessidade de introduzir, na organização } \\
\text { politicas efetivas de diversidade. }\end{array}$ \\
\hline
\end{tabular}




\begin{tabular}{|c|c|c|c|}
\hline $\begin{array}{l}\text { NASCIMENTO, ROCHA- } \\
\text { DE-OLIVEIRA (2014) }\end{array}$ & $\begin{array}{l}\text { Analisar as } \\
\text { características das } \\
\text { principais gerações de } \\
\text { servidores que atuam } \\
\text { numa IES do Rio de } \\
\text { Janeiro. }\end{array}$ & $\begin{array}{l}\text { Descritiva, qualitativa, } \\
\text { estudo de caso, foi } \\
\text { utilizado à entrevista } \\
\text { para coleta de dados. }\end{array}$ & $\begin{array}{l}\text { A sucessão geracional é importante para } \\
\text { promover a atualização de conhecimentos } \\
\text { necessários a instituição e a manutenção } \\
\text { vitais a sua permanência na sociedade. }\end{array}$ \\
\hline ROSA, ALVES (2014) & $\begin{array}{l}\text { Analisar como } \\
\text { o processo de } \\
\text { racialização em curso } \\
\text { no Brasil se relaciona } \\
\text { com a organização } \\
\text { da luta anti-racista no } \\
\text { mundo. }\end{array}$ & $\begin{array}{l}\text { Descritiva, qualitativa e } \\
\text { Revisão bibliográfica. }\end{array}$ & $\begin{array}{l}\text { A teoria dos frames nos ajudou a perceber } \\
\text { os aspectos subjetivos da organização, e } \\
\text { ação do movimento negro se alinharam ao } \\
\text { contexto de lutas globais contra o racismo. }\end{array}$ \\
\hline $\begin{array}{l}\text { REZENDE, CARVALHO- } \\
\text { FREITAS (2014) }\end{array}$ & $\begin{array}{l}\text { Verifica se existe } \\
\text { relação entre as crenças } \\
\text { dos profissionais de } \\
\text { RH sobre a deficiência, } \\
\text { as atitudes destes } \\
\text { frente às possibilidades } \\
\text { de ação no processo } \\
\text { de inclusão de pessoas } \\
\text { com deficiência. }\end{array}$ & $\begin{array}{l}\text { Descritiva, qualitativa } \\
\text { e quantitativa, pesquisa } \\
\text { de campo, foi utilizado } \\
\text { o questionário e a } \\
\text { entrevista para coleta } \\
\text { de dados. }\end{array}$ & $\begin{array}{l}\text { Os resultados apontam atitudes } \\
\text { diferenciadas dos profissionais de RH } \\
\text { frente à inclusão. Não havendo relações } \\
\text { entre concepções de deficiências e práticas } \\
\text { de RH inclusivas. }\end{array}$ \\
\hline $\begin{array}{l}\text { TONELLI, CEPELLOS, } \\
\text { SILVA (2014) }\end{array}$ & $\begin{array}{l}\text { Investigar como o } \\
\text { envelhecimento é } \\
\text { construído no mercado } \\
\text { de trabalho. }\end{array}$ & $\begin{array}{l}\text { Descritiva, qualitativa, } \\
\text { pesquisa de campo, foi } \\
\text { utilizado à entrevista } \\
\text { para coleta de dados. }\end{array}$ & $\begin{array}{l}\text { Constatou-se que nessas organizações as } \\
\text { pessoas não se reconhecem em sua idade } \\
\text { cronológica. }\end{array}$ \\
\hline $\begin{array}{l}\text { NASCIMENTO, } \\
\text { TEIXEIRA, OLIVEIRA } \\
(2014)\end{array}$ & $\begin{array}{l}\text { Compreender como } \\
\text { os discursos da mídia } \\
\text { eletrônica apresentam } \\
\text { reflexões das praticas } \\
\text { de resistências dos } \\
\text { jovens nos espaços } \\
\text { organizacionais dos } \\
\text { shoppings. }\end{array}$ & $\begin{array}{l}\text { Descritiva, qualitativa, } \\
\text { revisão bibliográfica e } \\
\text { análise do discurso. }\end{array}$ & $\begin{array}{l}\text { Os resultados destacam que as práticas } \\
\text { de resistência ampliam as fronteiras dos } \\
\text { espaços organizacionais na medida em que } \\
\text { desloca os pontos de controle e governança } \\
\text { das ações dos sujeitos e questionam à } \\
\text { construção de shopping center como } \\
\text { espaço de segregação avesso a grupos } \\
\text { sociais desfavorecidos. }\end{array}$ \\
\hline SILVA, CAPPELLE (2014) & $\begin{array}{l}\text { Apreender os sentidos } \\
\text { subjetivos do trabalho } \\
\text { produzidos por } \\
\text { mulheres prostitutas } \\
\text { no interior de Minas } \\
\text { Gerais. }\end{array}$ & $\begin{array}{l}\text { Descritiva, qualitativa, } \\
\text { pesquisa de campo, foi } \\
\text { utilizado à entrevista } \\
\text { para coleta de dados. }\end{array}$ & $\begin{array}{l}\text { Apreendeu-se sentidos subjetivos } \\
\text { relacionados ao trabalho na prostituição que } \\
\text { relacionam-se à violência, aborto induzido, } \\
\text { abandono, desconfiança, preconceito, } \\
\text { descriminação, medo, insegurança, etc.. }\end{array}$ \\
\hline
\end{tabular}




\begin{tabular}{|l|l|l|l|}
\hline & $\begin{array}{l}\text { Conhecer as } \\
\text { adaptações curriculares } \\
\text { realizadas no âmbito da } \\
\text { Educação Profissional } \\
\text { que atende pessoas } \\
\text { com deficiência. }\end{array}$ & $\begin{array}{l}\text { Exploratória, } \\
\text { qualitativa, pesquisa de } \\
\text { campo, foi utilizado à } \\
\text { entrevista para coleta } \\
\text { de dados. }\end{array}$ & $\begin{array}{l}\text { Os resultados obtidos demonstrou que } \\
\text { as ONGS se destacam em relação ao } \\
\text { sistema S pela diversidade de medidas } \\
\text { adaptativas empregadas no atendimento das } \\
\text { necessidades educacionais das pessoas. }\end{array}$ \\
\hline $\begin{array}{l}\text { QUEIROZ, REGO, } \\
\text { IRIGARAY (2014) }\end{array}$ & $\begin{array}{l}\text { Mostrar como a cultura } \\
\text { local influencia a } \\
\text { pratica profissional dos } \\
\text { PMs. }\end{array}$ & $\begin{array}{l}\text { Descritiva, qualitativa, } \\
\text { pesquisa de campo, foi } \\
\text { utilizado à entrevista } \\
\text { para coleta de dados. }\end{array}$ & $\begin{array}{l}\text { A pesquisa revelou que é possível inferir a } \\
\text { existência de barreiras invisíveis que limitam } \\
\text { um PM para atuar nessa carreira. }\end{array}$ \\
\hline
\end{tabular}

Fonte: Dados da pesquisa, 2015.

Notamos que relacionado à diversidade nas organizações há estudos com vários enfoques, com destaque para as pessoas com necessidades especiais; raça e etnia; inclusão de pessoas com orientações sexuais diversas, gays, lésbica, travestis, e resocialização de ex-detentos; bem como aspectos relacionados a diferença de idades nas organizações, bem como diferença de gênero.

Quadro 2 . Pesquisas com ênfase nas questões de gênero, no EnEO, no período de 2000 - 2014.

\begin{tabular}{|l|l|l|l|}
\hline AUTOR (ES) & OBJETIVOS & METODOLOGIA & $\begin{array}{l}\text { CONSIDERAÇÕES/ } \\
\text { CONCLUSÃO }\end{array}$ \\
\hline SILVA, VIEIRA (2004) & $\begin{array}{l}\text { Analisar a influência dos } \\
\text { contextos ambiental e } \\
\text { organizacional sobre a } \\
\text { interpretação de gêneros e } \\
\text { suas consequências para as } \\
\text { práticas gerenciais. }\end{array}$ & $\begin{array}{l}\text { Exploratória, qualitativa, } \\
\text { estudo de caso, foi utilizado } \\
\text { o questionário para coleta de } \\
\text { dados. }\end{array}$ & $\begin{array}{l}\text { Os resultados não apontaram } \\
\text { diferenças significativas entre } \\
\text { os gerentes masculinos e } \\
\text { femininos em nenhuma das } \\
\text { analises efetuadas. }\end{array}$ \\
\hline MÂCEDO, et. al., (2004) & $\begin{array}{l}\text { Levantar dados relativos à } \\
\text { inclusão/exclusão da mulher } \\
\text { no processo sucessório de } \\
\text { organização familiar. }\end{array}$ & $\begin{array}{l}\text { Descritiva e exploratória, } \\
\text { qualitativa e quantitativa, } \\
\text { estudo de caso, foi utilizado } \\
\text { à entrevista para coleta de } \\
\text { dados. }\end{array}$ & $\begin{array}{l}\text { Como resultado tem-se que, } \\
\text { em decorrência de traços } \\
\text { da cultura brasileira e das } \\
\text { organizações pesquisadas, } \\
\text { ocorre a exclusão da mulher } \\
\text { no processo sucessório de } \\
\text { organizações familiares. }\end{array}$ \\
\hline
\end{tabular}




\begin{tabular}{|c|c|c|c|}
\hline $\begin{array}{l}\text { MÂCEDO, MÂCEDO } \\
(2004)\end{array}$ & $\begin{array}{l}\text { Buscar apreender como } \\
\text { as relações de gênero são } \\
\text { percebidas no discurso } \\
\text { de homens e mulheres no } \\
\text { contexto organizacional. }\end{array}$ & $\begin{array}{l}\text { Descritiva, qualitativa e } \\
\text { quantitativa, estudo de } \\
\text { caso, foi utilizado analise } \\
\text { documental e entrevista para } \\
\text { coleta de dados. }\end{array}$ & $\begin{array}{l}\text { O discurso de homens } \\
\text { sustenta a cultura machista, } \\
\text { mediado pela ideologia } \\
\text { responsável por naturalizar } \\
\text { relações de domínio e } \\
\text { subordinação feminina; e } \\
\text { um discurso feminino que } \\
\text { se diz consciente de todos } \\
\text { os processos de opressão, } \\
\text { discriminação e desigualdade, } \\
\text { mas que se submete à } \\
\text { organização por necessidade } \\
\text { de sobrevivência. }\end{array}$ \\
\hline $\begin{array}{l}\text { BRUNSTEIN, COELHO JR. } \\
(2006)\end{array}$ & $\begin{array}{l}\text { Analisar as estratégias de } \\
\text { negociação com a condição } \\
\text { de gênero que as mulheres } \\
\text { executivas utilizam na } \\
\text { construção de suas trajetórias } \\
\text { profissionais. }\end{array}$ & $\begin{array}{l}\text { Descritiva, qualitativa, } \\
\text { estudo de caso, foi utilizado } \\
\text { à entrevista para coleta de } \\
\text { dados. }\end{array}$ & $\begin{array}{l}\text { Evidenciaram que os } \\
\text { mecanismos adotados pelas } \\
\text { mulheres para ascender em } \\
\text { um universo de trabalho } \\
\text { predominantemente } \\
\text { masculino reflete uma } \\
\text { forma peculiar de lidar com } \\
\text { a relação gênero, a qual } \\
\text { expressa um jeitinho da } \\
\text { cultura brasileira. }\end{array}$ \\
\hline $\begin{array}{l}\text { MAGESTE, MENDES, } \\
\text { CAPELLE (2006) }\end{array}$ & $\begin{array}{l}\text { Identificar, descrever e } \\
\text { analisar as representações do } \\
\text { trabalho feminino em quatro } \\
\text { filmes brasileiros escolhidos } \\
\text { em função de sua temática } \\
\text { principal: o trabalho da } \\
\text { mulher. }\end{array}$ & $\begin{array}{l}\text { Descritiva, qualitativa e } \\
\text { analise fílmica. }\end{array}$ & $\begin{array}{l}\text { Pode-se perceber que é } \\
\text { recorrente a representação } \\
\text { do trabalho feminino como } \\
\text { secundário na vida da mulher. } \\
\text { A mulher se dedica mais ao } \\
\text { trabalho quando não possui } \\
\text { um relacionamento amoroso. } \\
\text { O instinto materno e a } \\
\text { vontade de formar família } \\
\text { supera a necessidade de } \\
\text { sucesso profissional. }\end{array}$ \\
\hline $\begin{array}{l}\text { MIRANDA, SILVEIRA, } \\
\text { HOELTGEBAUM (2008) }\end{array}$ & $\begin{array}{l}\text { O estudo das gestoras de uma } \\
\text { IES quanto às características } \\
\text { pessoais, profissionais e } \\
\text { empreendedoras neste tipo de } \\
\text { organização. }\end{array}$ & $\begin{array}{l}\text { Exploratória, qualitativa, } \\
\text { estudo de caso, foi utilizado } \\
\text { analise documental e } \\
\text { entrevista para coleta de } \\
\text { dados. }\end{array}$ & $\begin{array}{l}\text { Na IES estudada há uma } \\
\text { situação favorável para } \\
\text { a igualdade dos direitos } \\
\text { e deveres entre gêneros. } \\
\text { Percebeu-se que a inclusão } \\
\text { da mulher nas instâncias } \\
\text { decisórias ocorre de maneira } \\
\text { gradativa, especialmente nos } \\
\text { cargos eletivos. }\end{array}$ \\
\hline
\end{tabular}




\begin{tabular}{|c|c|c|c|}
\hline FIGUEIREDO (2010) & $\begin{array}{l}\text { Discorrer sobre a construção } \\
\text { social da noção de gênero e a } \\
\text { sua influência determinante } \\
\text { sobre a organização social. }\end{array}$ & $\begin{array}{l}\text { Descritiva, qualitativa e e } \\
\text { revisão bibliográfica. }\end{array}$ & $\begin{array}{l}\text { A dicotomia entre feminino e } \\
\text { masculino não permite ainda } \\
\text { a existência de um espaço de } \\
\text { dialogo entre gêneros. }\end{array}$ \\
\hline SILVA, RUFINO (2010) & $\begin{array}{l}\text { Analisar o movimento } \\
\text { feminista e as articulações } \\
\text { de mulheres nos seus } \\
\text { vários momentos históricos } \\
\text { interessa apontar a influência } \\
\text { dessas teorias na constituição } \\
\text { destes grupos e de sua } \\
\text { atuação. }\end{array}$ & $\begin{array}{l}\text { Descritiva, qualitativa, estudo } \\
\text { de caso, foi utilizado analise } \\
\text { documental e entrevista para } \\
\text { coleta de dados. }\end{array}$ & $\begin{array}{l}\text { Existem influências na } \\
\text { trajetória e formação dos } \\
\text { grupos feministas paraibanos } \\
\text { tanto dos movimentos } \\
\text { internacionalmente } \\
\text { conhecidos, assim como das } \\
\text { teorias caracterizadas no } \\
\text { modelo escolhido. }\end{array}$ \\
\hline $\begin{array}{l}\text { SANTOS, GUEVARA, } \\
\text { AMORIM (2010) }\end{array}$ & $\begin{array}{l}\text { Avaliar o impacto do nível } \\
\text { de instrução, idade e gênero, } \\
\text { na percepção moral dos } \\
\text { indivíduos nas organizações. }\end{array}$ & $\begin{array}{l}\text { Exploratória, quantitativa, } \\
\text { estudo de caso, foi utilizado } \\
\text { questionário e entrevista para } \\
\text { a coleta de dados. }\end{array}$ & $\begin{array}{l}\text { Os resultados indicam que a } \\
\text { variável instrução em geral } \\
\text { parece ter maior influência } \\
\text { nos indicadores de percepção } \\
\text { moral, o que significa que } \\
\text { quanto menor o grau de } \\
\text { instrução do individuo } \\
\text { menos estruturado está sua } \\
\text { percepção moral. A idade } \\
\text { e o gênero também tem } \\
\text { importância, porém em } \\
\text { menor escala. }\end{array}$ \\
\hline $\begin{array}{l}\text { STROBINO, TEIXEIRA } \\
(2010)\end{array}$ & $\begin{array}{l}\text { Apresentar os conflitos } \\
\text { trabalho-família percebidas } \\
\text { por duas empresarias da } \\
\text { construção civil da cidade de } \\
\text { Curitiba. }\end{array}$ & $\begin{array}{l}\text { Descritiva, qualitativa, estudos } \\
\text { de multicasos, foi utilizado à } \\
\text { entrevista e observação para } \\
\text { coleta de dados. }\end{array}$ & $\begin{array}{l}\text { O fator tempo o mais citado } \\
\text { como gerador de conflito } \\
\text { trabalho-família e o controle } \\
\text { emocional, como a ação mais } \\
\text { citada como atenuante destes } \\
\text { conflitos. }\end{array}$ \\
\hline $\begin{array}{l}\text { ZAMPIER, TAKAHASHI } \\
(2010)\end{array}$ & $\begin{array}{l}\text { Analisar como os } \\
\text { docentes com perfil } \\
\text { intraempreendedor, lidam } \\
\text { com os conflitos oriundos } \\
\text { da relação trabalho-família } \\
\text { no desenvolvimento } \\
\text { das competências } \\
\text { empreendedoras. }\end{array}$ & $\begin{array}{l}\text { Descritiva, qualitativa, estudo } \\
\text { de caso, foi utilizado analise } \\
\text { documental e entrevista para } \\
\text { coleta de dados. }\end{array}$ & $\begin{array}{l}\text { A pesquisa revelou que } \\
\text { as docentes entrevistadas } \\
\text { gostam de suas atividades, } \\
\text { e por isso, acabam por } \\
\text { entregar maior dedicação para } \\
\text { o desenvolvimento destas } \\
\text { competências, e buscam } \\
\text { atenuar possíveis conflitos } \\
\text { entre o trabalho e a família } \\
\text { administrando o tempo e } \\
\text { compartilhando as atividades } \\
\text { familiares. }\end{array}$ \\
\hline
\end{tabular}




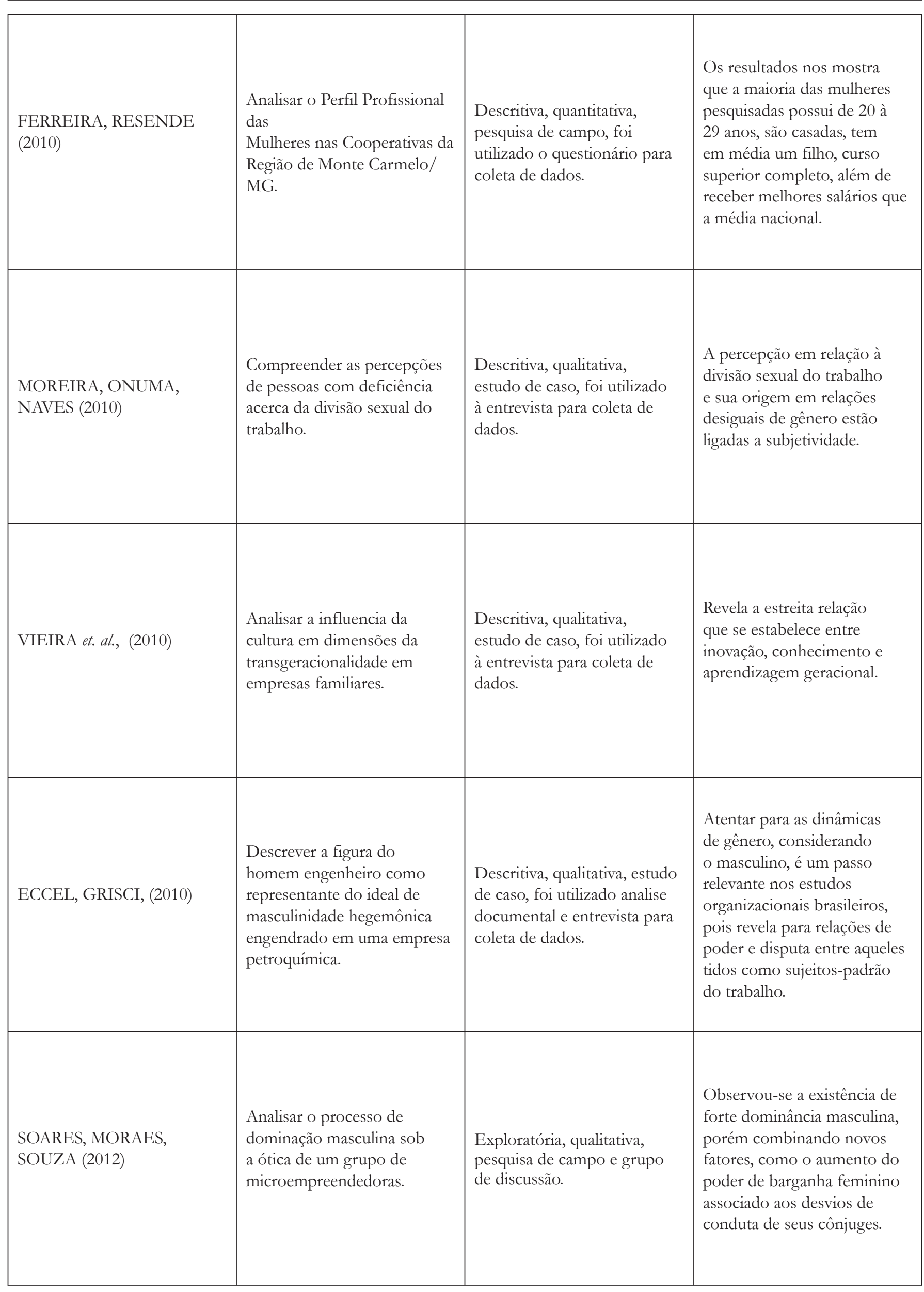




\begin{tabular}{|c|c|c|c|}
\hline $\begin{array}{l}\text { FONTOURA, OLIVEIRA } \\
\text { (2014) }\end{array}$ & $\begin{array}{l}\text { Como os construtos de } \\
\text { classes, gênero e idade } \\
\text { engendram sua constituição. }\end{array}$ & $\begin{array}{l}\text { Descritiva, qualitativa e } \\
\text { revisão bibliográfica. }\end{array}$ & $\begin{array}{l}\text { Reforça-se a importância } \\
\text { de considerar o mercado de } \\
\text { trabalho como um espaço } \\
\text { dinâmico onde a conduta dos } \\
\text { atores envolvidos é definida } \\
\text { com base em crenças, valores } \\
\text { e regras compartilhadas. }\end{array}$ \\
\hline $\begin{array}{l}\text { ANDRADE, } \\
\text { MACEDO, OLIVEIRA } \\
\text { (2014) }\end{array}$ & $\begin{array}{l}\text { Visa realizar um mapeamento } \\
\text { preliminar das atividades } \\
\text { desenvolvidas pelos grupos } \\
\text { de pesquisa e compreender as } \\
\text { relações entre eles. }\end{array}$ & $\begin{array}{l}\text { Descritiva, qualitativa } \\
\text { e quantitativa, revisão } \\
\text { bibliográfica, foi utilizado a } \\
\text { bibliometria para analise dos } \\
\text { dados. }\end{array}$ & $\begin{array}{l}\text { Verificamos quão recente } \\
\text { é a maioria dos grupos de } \\
\text { pesquisa em administração } \\
\text { que lidam com gênero, apesar } \\
\text { do relevante aumento do } \\
\text { número de grupos que tratam } \\
\text { do tema. }\end{array}$ \\
\hline MATOS et. al., (2014) & $\begin{array}{l}\text { Compreender que tipo de } \\
\text { resultados se podem esperar } \\
\text { quando o empreendedorismo } \\
\text { é uma atividade de mudança } \\
\text { social. }\end{array}$ & $\begin{array}{l}\text { Descritiva, qualitativa e } \\
\text { quantitativa, estudo de caso, } \\
\text { foi utilizado à entrevista para } \\
\text { coleta de dados. }\end{array}$ & $\begin{array}{l}\text { O sentido de emancipação } \\
\text { através da atividade } \\
\text { empreendedora ainda é } \\
\text { limitado à norma masculina } \\
\text { do empreendedorismo, que } \\
\text { restringe as possiblidades de } \\
\text { autonomia das mulheres e } \\
\text { coíbe através do preconceito } \\
\text { a manifestação da } \\
\text { homosexualidade. }\end{array}$ \\
\hline MEDEIROS, SILVA (2014) & $\begin{array}{l}\text { Discutir o apelo a um ideal de } \\
\text { masculinidade relacionado ao } \\
\text { consumo de carne. }\end{array}$ & $\begin{array}{l}\text { Descritiva, qualitativa e } \\
\text { revisão bibliográfica. }\end{array}$ & $\begin{array}{l}\text { Pode-se considerar que o } \\
\text { consumo de carne seria } \\
\text { uma forma de reafirmar } \\
\text { a masculinidade do } \\
\text { consumidor, ao mesmo } \\
\text { tempo que ajuda a reforçar } \\
\text { um status quo do homem } \\
\text { como sexo forte. }\end{array}$ \\
\hline FELIPE et. al., (2014) & $\begin{array}{l}\text { Verificar a existência do } \\
\text { empoderamento e ou } \\
\text { violência simbólica na } \\
\text { percepção de mulheres } \\
\text { docentes. }\end{array}$ & $\begin{array}{l}\text { Descritiva, qualitativa, } \\
\text { estudo de caso, foi utilizado } \\
\text { à entrevista para coleta de } \\
\text { dados. }\end{array}$ & $\begin{array}{l}\text { Os resultados apontaram } \\
\text { que as docentes entrevistadas } \\
\text { estão em processo de } \\
\text { empoderamento, contanto, } \\
\text { ainda são vitimas de violência } \\
\text { simbólica e tem dificuldade } \\
\text { de reconhecer esse fato. }\end{array}$ \\
\hline & & & \\
\hline
\end{tabular}




\begin{tabular}{|c|c|c|c|}
\hline $\begin{array}{l}\text { NASSIF, ANDREASSI, } \\
\text { TONELLI (2014) }\end{array}$ & $\begin{array}{l}\text { Analisar situações críticas } \\
\text { vividas por mulheres } \\
\text { empreendedoras e entender } \\
\text { como elas superam tais } \\
\text { situação. }\end{array}$ & $\begin{array}{l}\text { Exploratória, qualitativa, } \\
\text { pesquisa de campo, foi } \\
\text { utilizado o Formulário - } \\
\text { Técnica de Índice Crítico, } \\
\text { para coleta e analise dos } \\
\text { dados. }\end{array}$ & $\begin{array}{l}\text { Constatou-se que nos } \\
\text { incidentes críticos das } \\
\text { empreendedoras, os aspectos } \\
\text { pessoais confundem-se com } \\
\text { os profissionais, acarretando } \\
\text { problemas desafiadores no } \\
\text { âmbito pessoal e profissional. }\end{array}$ \\
\hline
\end{tabular}

Fonte: Dados da pesquisa, 2015.

No aspecto gênero, o assunto mais debatido ainda trata-se da discriminação das mulheres no mercado de trabalho.

\section{Características Gerais das Publicações}

A seguir serão apresentadas as características relevantes das publicações estudadas: distribuição de artigos por ano de publicação, distribuição de artigos por temas de interesse no ano de 2014, formação máxima dos autores por publicação, quantidade de autores por produção científica, instituições vinculadas pelos autores, e também aspectos metodológicos das publicações: quanto aos objetivos da pesquisa, quanto à abordagem, quanto aos procedimentos, e os instrumentos utilizados para a coleta de dados.

Tabela 1. Distribuição de artigos por ano

\begin{tabular}{|c|c|c|c|}
\hline Ano & $\mathbf{N}^{\mathbf{0}}$ de publicações no & \multicolumn{2}{|c|}{$\mathbf{N}^{\mathbf{o}}$ de publicações sobre os temas } \\
EnEO & 53 & 00 & 00 \\
\hline 2000 & 72 & 01 & 00 \\
\hline 2002 & 146 & 02 & 03 \\
\hline 2004 & 130 & 03 & 02 \\
\hline 2006 & 162 & 02 & 01 \\
\hline 2008 & 174 & 02 & 08 \\
\hline 2010 & 132 & 05 & 02 \\
\hline 2012 & 139 & 09 & 06 \\
\hline 2014 & $\mathbf{1 0 0 8}$ & $\mathbf{2 4}$ & $\mathbf{2 2}$ \\
\hline Total & & 24 & 02 \\
\hline
\end{tabular}

Fonte: Dados da pesquisa, 2015.

De acordo com a relação de publicações por ano, observa-se que o Encontro de Estudos Organizacionais da ANPAD - EnEO, acontece de dois em dois anos, sendo no ano de 2014 que aconteceu o último encontro. Nota-se ainda que a partir do ano de 2.010, ocorreu um aumento expressivo nas publicações sobre os temas gênero e diversidade, sendo o ano de 2014 com maior enfoque, com nove publicações sobre diversidade e seis publicações sobre gênero. 
Figura 1. Distribuição de artigos por temas de interesse, no EnEO, no período de 2014.

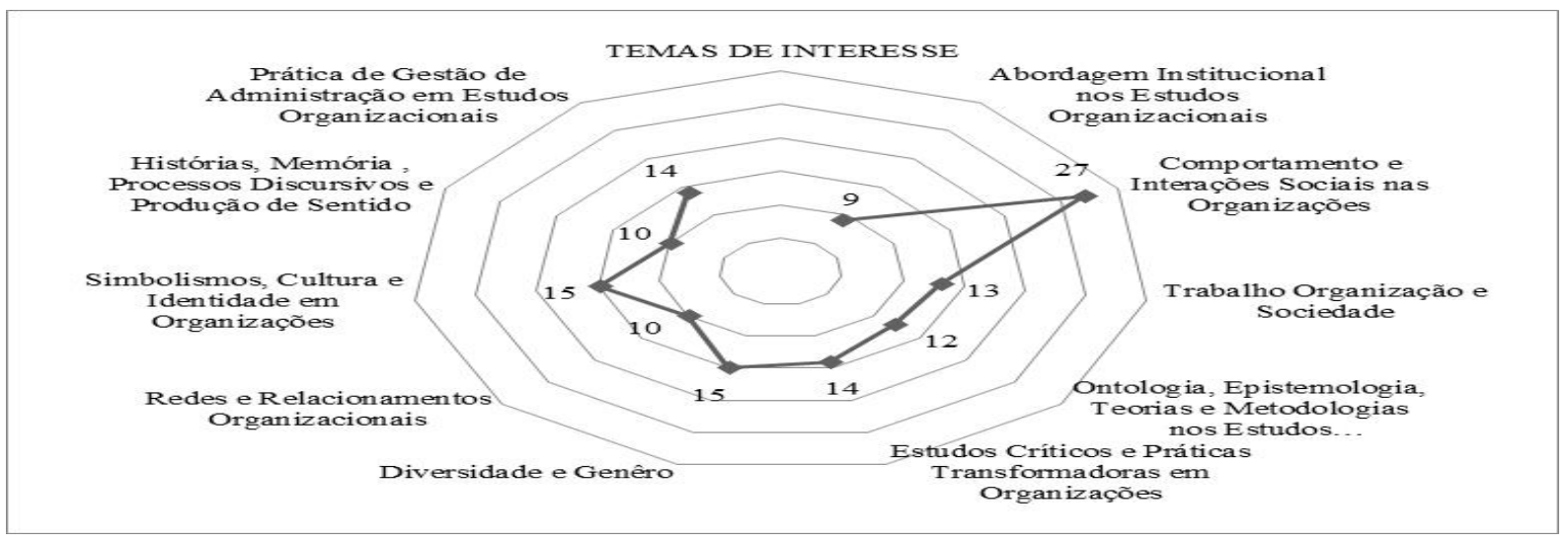

Fonte: Dados da pesquisa, 2015.

A partir do VIII Encontro de Estudos Organizacionais da ANPAD, EnEO de 2014, o mesmo foi subdivido em temas de interesses, sendo possível analisar as publicações por temas de interesse. Assim no EnEO de 2014, dentre os temas de interesse nota-se que o tema Comportamento e Interações Sociais nas Organizações que foi mais abordado com 27 publicações, seguidos de Simbolismos, Culturas e Identidades nas organizações e Diversidade e Gênero com 15 publicações respectivamente.

Figura 2 . Formação máxima dos autores por produção científica.

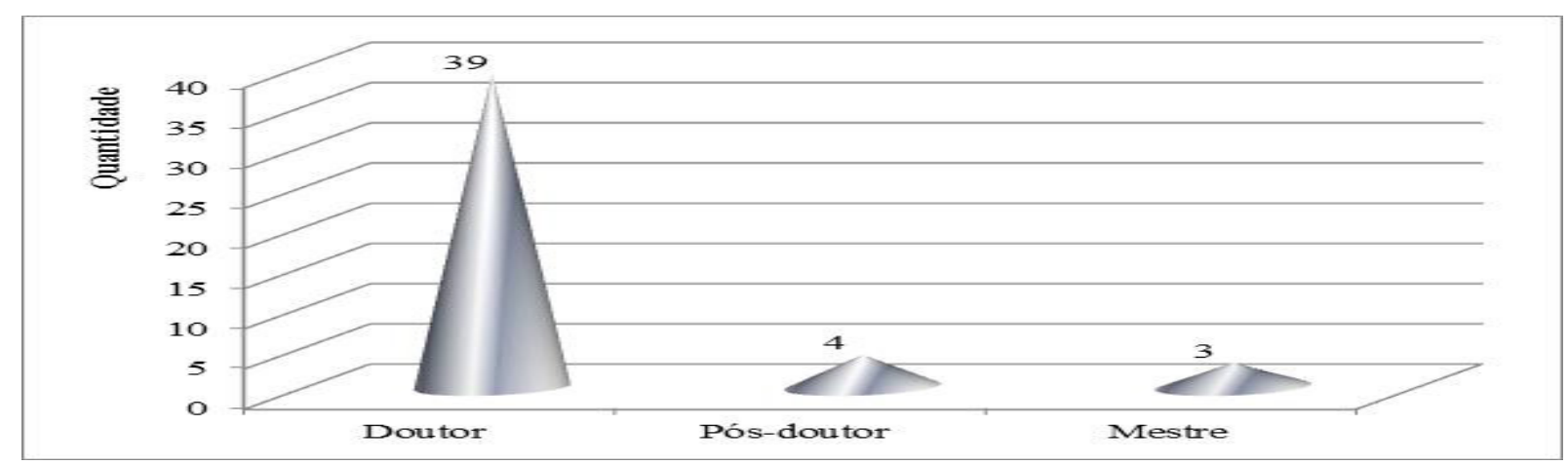

Fonte: Dados da pesquisa, 2015.

Relacionado à formação máxima dos autores de cada produção acadêmica/cientifica analisada, ficou constatado que em trinta e nove (39) produções apresentavam um doutor como autor ou participante, em quatro (04) produções teve a participação e/ou autores com formação em pós-doutorado, em três (03) produções cientificas/acadêmicas constavam a participação e/ou autores mestres.

Figura 3 . Quantidade de autores por produção científica.

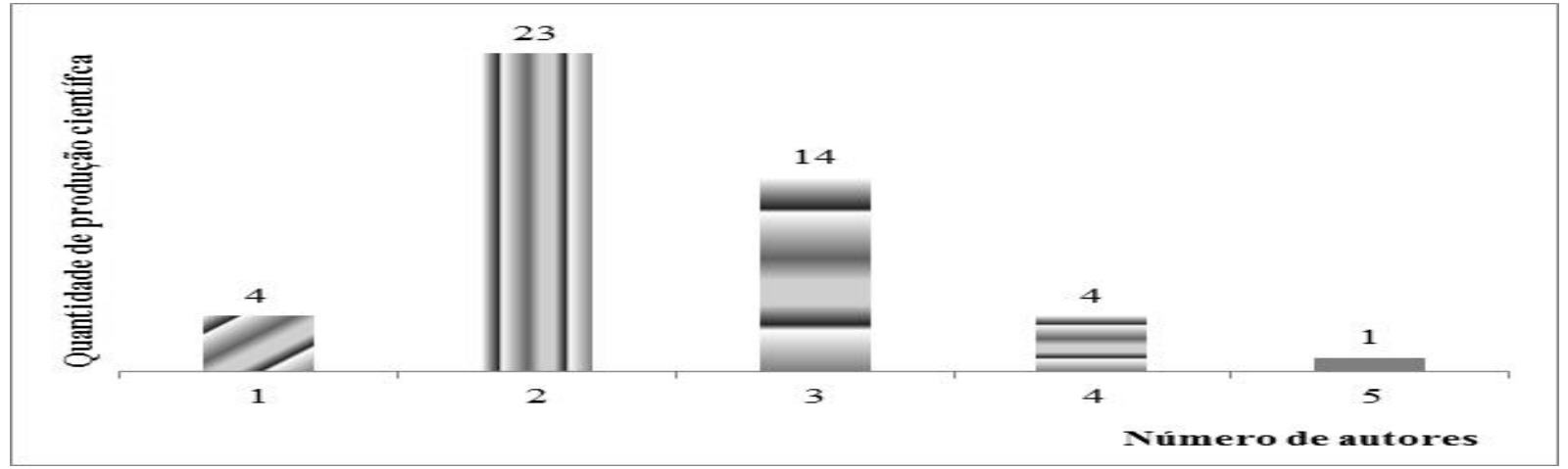

Fonte: Dados da pesquisa, 2015. 
Durante o período de 2000 a 2014, a amostra selecionada de quarenta e cinco (46) produções acadêmicas e cientificas, apresentam quatro (04) produções cientificas com apenas um (1) autor, apresentam também vinte e três (23) produções cientificas com dois (2) autores, quatorze (14) produções cientificas com três (03) autores, quatro produções cientificas com quatro (04) autores, e apenas uma (01) produção científica com cinco (05) autores.

Nota-se que os trabalhos em sua maioria são obras relacionados com os cursos de mestrados e doutorados, com a participação de orientadores, e às vezes também com co-orientadores.

Figura 4 . Frequências das palavras presentes nos títulos dos artigos.

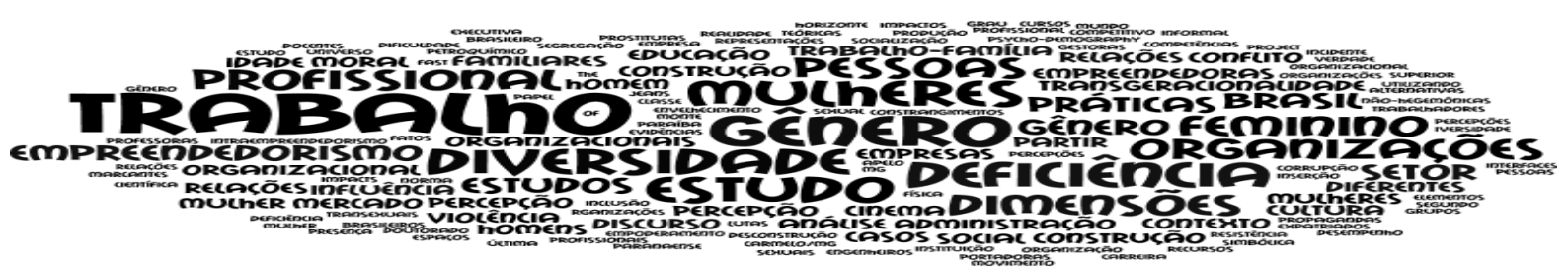

Fonte: Dados da pesquisa, 2015.

Percebemos que as palavras: trabalho, gênero, diversidade, estudo, mulheres, deficiência, dimensões, feminino, organizações, profissional, dentre outras foram as mais abordadas.

Figura 5 . Instituições vinculadas pelos autores.

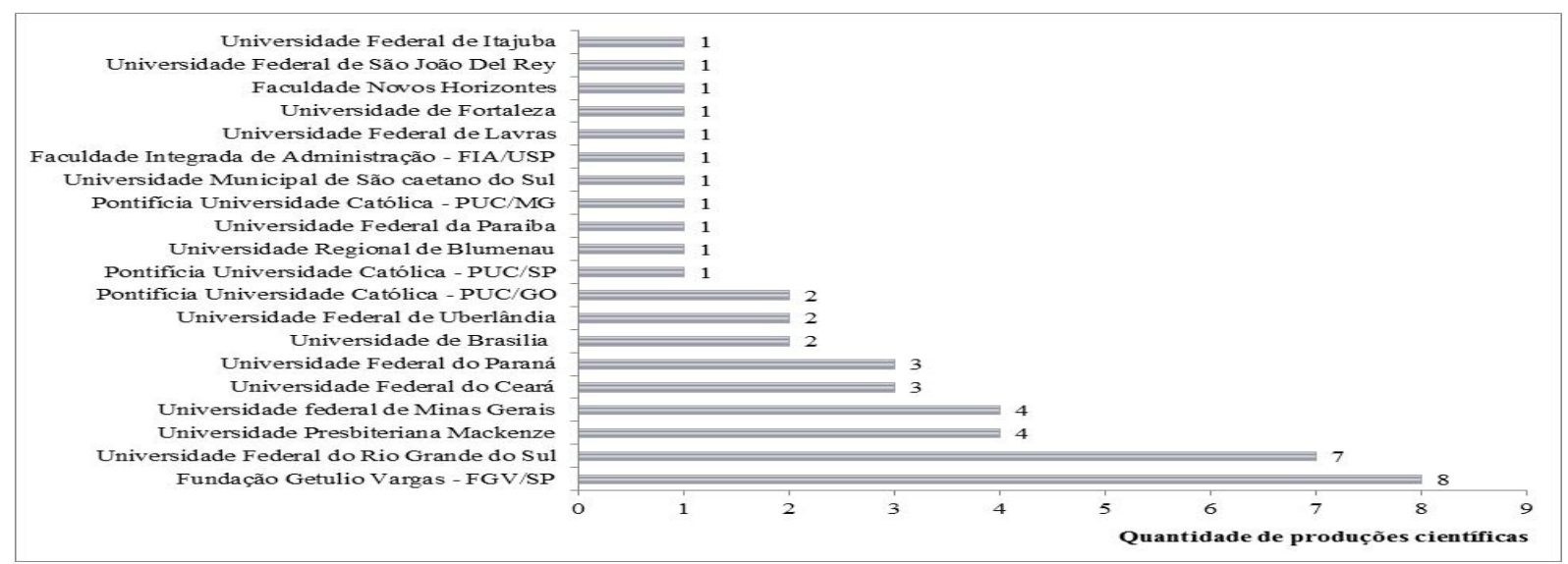

Fonte: Dados da pesquisa, 2015.

Dentre as Instituições de Ensino Superior (IES) vinculadas pelos autores, que discutem sobre a temática gênero e diversidade, no EnEO da ANPAD, constata-se que a Fundação Getúlio Vargas - FGV/SP foi a que teve maior número de produções científicas, oito (08) produções científicas; seguida da Universidade Federal do Rio Grande do Sul com sete (07) produções cientificas; Universidade Presbiteriana Mackenze e Universidade Federal de Minas Gerais com quatro (04) produções cientificas; a Universidade Federal do Paraná e a Universidade Federal do Ceará com três (03) produções cientificas; a Pontifícia Universidade Católica - PUC/GO, a Universidade Federal de Uberlândia e a Universidade de Brasília - UNB, com duas (02) produções científicas cada, e as demais instituições relacionadas com uma (01) produção científica/acadêmica.

A metodologia utilizada pelos autores nas produções acadêmicas e/ou científicas, selecionadas para analise, observando quanto aos objetivos, à abordagem, os procedimentos e os instrumentos utilizados, serão tratadas a seguir. 
Figura 6 . Metodologia de pesquisa utilizada, quanto aos objetivos.

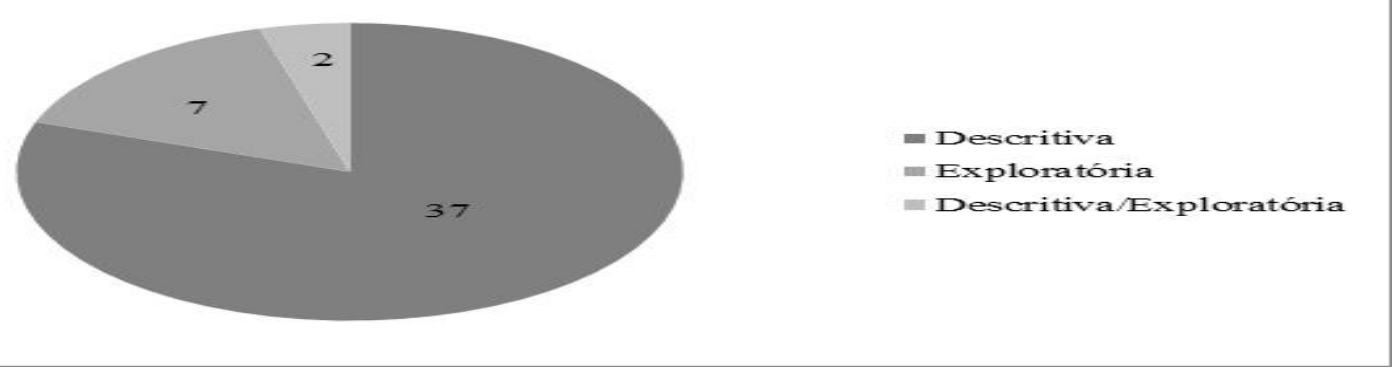

Fonte: Dados da pesquisa, 2015.

Quanto aos objetivos da pesquisa, dentre as quarenta e seis (46) produções cientificas e/ou acadêmicas, em trinta e sete (37) produções, os autores classificaram a pesquisa como sendo descritiva; em sete (07) produções, como sendo pesquisa exploratória; e em duas (02) produções, descritiva e exploratória.

Figura 7 . Metodologia de pesquisa utilizada, quanto à abordagem.

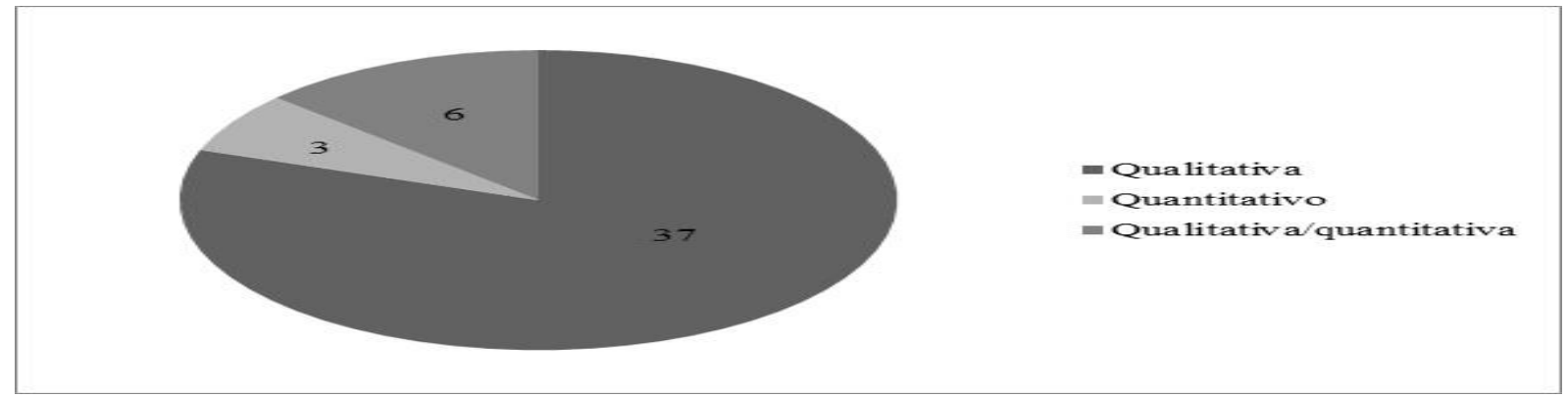

Fonte: Dados da pesquisa, 2015.

Quanto á abordagem, as pesquisas selecionadas foram classificadas pelos autores, como pesquisas qualitativas em trinta e sete (37) produções; quantitativas em três (03) produções; e qualitativa e quantitativa ou mista em seis (06) produções científicas e acadêmicas.

Figura 8 . Metodologia de pesquisa utilizada, quanto aos procedimentos.

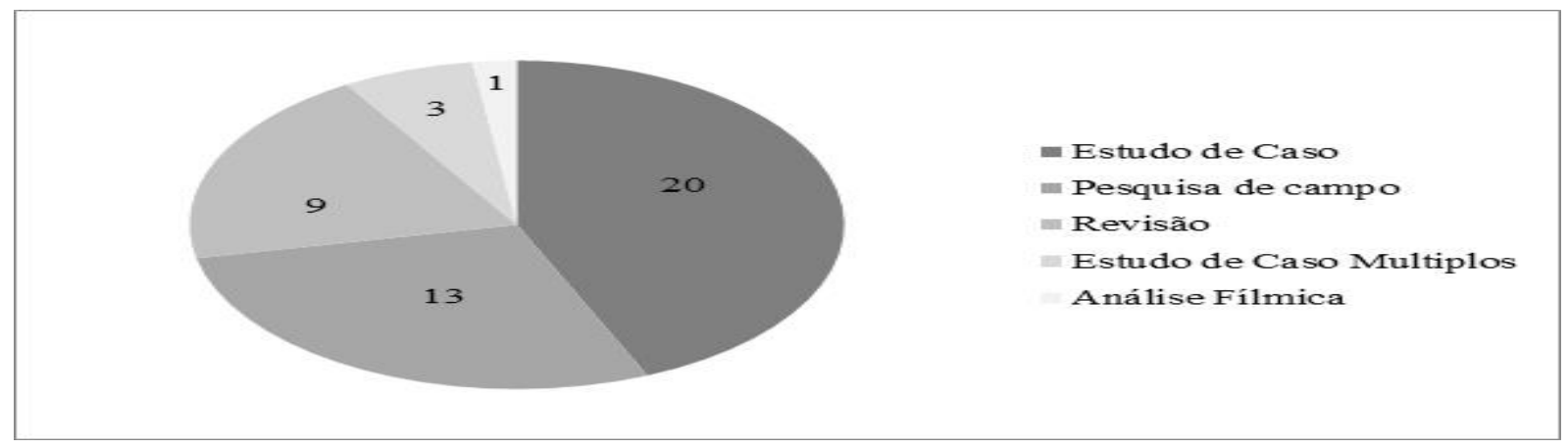

Fonte: Dados da pesquisa, 2015.

Quanto aos procedimentos de pesquisa, observamos que entre as quarenta e seis (46) produções científicas e acadêmicas, vinte (20) produções são estudos de casos; treze (13) são pesquisa de campo; nove (07) são revisão bibliográfica; três (03) são estudo de casos múltiplos e uma (01) análise fílmica. 
Figura 9. Metodologia de pesquisa utilizada, quanto aos instrumentos de pesquisa utilizados.

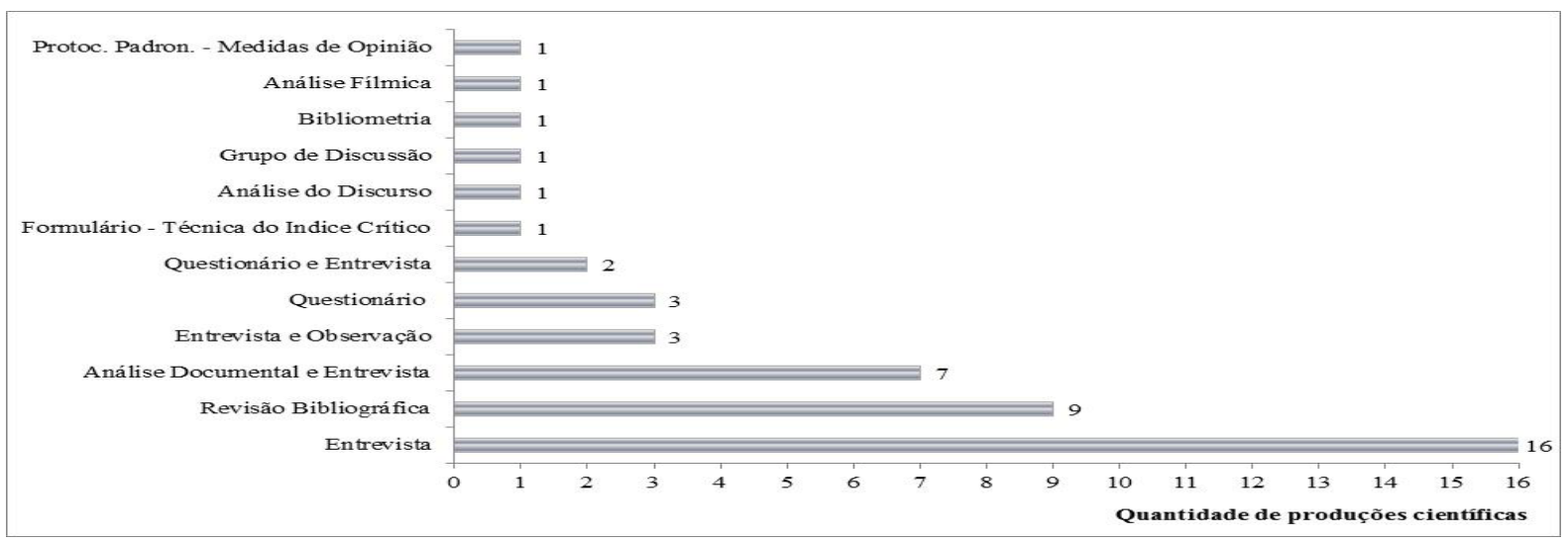

Fonte: Dados da pesquisa, 2015.

Quanto aos instrumentos de pesquisa utilizados, observamos que entre as quarenta e seis (46) produções científicas e acadêmicas, dezesseis (16) produções científicas utilizaram a entrevista para a coleta de dados; nove (09) produções científicas foi revisão bibliográfica; sete (07) produções científicas usaram a análise documental e entrevista. Já em três (03) produções científicas foram aplicados questionários para a coleta de dados; e novamente em três (03) produções científicas foram utilizado entrevista e observação; em duas (02) produções científicas utilizou o questionário e a entrevista para a coleta de dados, e os demais instrumentos apresentados: formulário - técnica do índice crítico; análise do discurso; grupo de discussão; bibliometria, análise fílmica e protocolo padronizado - medidas de opinião; foi utilizado em uma (01) produção cientifica respectivamente.

\section{Conclusão}

Os resultados encontrados demonstraram a diversidade de estudos recentes que tratam dos temas em questão, tanto da diversidade como do gênero. Já abordado por Andrade, Macedo e Oliveira (2014) que verificaram quão recente é a maioria dos grupos de pesquisa em administração que lidam com gênero, apesar do relevante aumento do número de grupos que tratam do tema. Costa e Ferreira (2006) relataram que os temas: raça e de etnia e inclusão de pessoas com orientações sexuais diversas permanecem praticamente inexplorados nos estudos organizacionais.

Relacionado a diversidade nas organizações, observamos que é uma falsa novidade conforme abordam Silva e Alves (2002) que a diversidade não muda o valor das pessoas, pois estas continuam a ser consideradas sob a ótica da produção, e estende-se até os dias atuais. Todavia faz necessário aprofundar a discussão sobre a diversidade nas organizações, a importância de assuntos relacionados à promoção de justiça e bem-estar social, bem como traçar políticas que sejam de interesses tanto dos empregados como da organização. O trabalho de Lima, Vieira Junior, Lima (2014) aponta a necessidade de introduzir, nas organizações políticas efetivas de diversidade.

Conforme os relatos dos autores ficam claro que a inclusão das pessoas com necessidades especiais no mercado de trabalho, encontram-se alguns obstáculos como a discriminação, falta de apoio social, abordados por Siqueira e Prelorentzou (2008), e Doval e Haro (2006) relatam as barreiras impostas pelas organizações capitalistas, e não necessariamente as limitações físicas. Além da necessidade de políticas organizacionais com foco na diversidade, a melhoria do ambiente de trabalho é primordial. Gaspar et. al. (2012) explicam que o programa de qualidade de vida no trabalho é viável nas organizações e pode proporcionar efetivamente a satisfação das pessoas com deficiência sob o atual contexto da diversidade.

Outro dado relevante abordado por Siqueira e Felows (2006) é que as empresas se deparam cada vez mais com a questão de empregados gays e lésbicas, sendo necessário o desenvolvimento de políticas que sejam de interesses 
mútuos. Já Irigaray (2010) aborda que as travestis e transexuais que conseguem entrar no mercado de trabalho formal são vitimas de agressões, violência e intolerância por parte dos colegas de trabalho.

Diante destes comentários podemos concluir que o ponto fundamental para a inclusão e diversificação no ambiente de trabalho, além de políticas exclusivas para a diversidade, precisa de uma mudança na cultura organizacional passando de uma cultura tradicionalista para uma cultura aberta a mudanças e inovações.

Nos assuntos relacionados ao gênero a inserção da mulher no mercado de trabalho foi o mais comentado. Ferraz, Mapurunga e Ferraz (2012) explicam que a inserção tardia mostra-se associado com sentimento de inferioridade e de frustração. Visão reafirmada nos trabalhos de Mâcedo e Mâcedo (2004) citam que o discurso feminino se diz consciente de todos os processos de opressão, discriminação e desigualdade, mas que se submete à organização por necessidade de sobrevivência. Outro fator que merece destaque foi abordado por Zampier, Takahashi (2010) pode-se perceber que é recorrente a representação do trabalho feminino como secundário na vida da mulher. $\mathrm{O}$ instinto materno e a vontade de formar família supera a necessidade de sucesso profissional.

Mesmo assim com tantas ponderações sobre as mulheres no mercado de trabalho percebemos que as mulheres estão ganhando espaço, superando suas dificuldades, e mostrando que são potenciais empreendedoras e construindo suas carreiras.

Percebemos que os estudos relacionados às pessoas nas organizações, como diversidade, gênero, entre outros, em comparação com as práticas organizacionais, demonstram que os estudos ainda não passam de ilusão e sentimentalismo. Sendo que a realidade organizacional é bem diferente, a visão capitalista prevalece, por exemplo, a inclusão das pessoas com necessidades especiais no mercado de trabalho ainda precisa ser garantido por leis e benefícios empresariais para que ocorram. Como mostram Gaspar, et. al., (2012) que a lei 8.213 contribuiu significativamente para o aumento da participação de pessoas com necessidades especiais nas empresas e trouxe à tona a questão da diversidade.

A realidade empresarial lentamente está mudando, compreendendo que a diversidade na organização éalgo que contribui para o crescimento e desenvolvimento das mesmas, pois a questão diversidade é ampla, envolvem raças, gênero, idade, cultura, sexualidade, entre vários outros aspectos.

Através desta diferenciação, as organizações podem conseguir atingir melhor seus objetivos organizacionais na ótica de produção, do que em um ambiente homogêneo, com visões e entendimento diferenciados. E independente de conseguirem vantagens competitivas, compreender a diversidade organizacional é algo primordial, pois as empresas vivem em um ambiente de diversidades.

\section{Referências Bỉbliográficas}

ANDRADE, L. F. S.; MACEDO, A. S.; OLIVEIRA, M. L. S.. A produção científica em gênero no Brasil: um panorama dos grupos de pesquisa de administração. In: Encontro de Estudos Organizacionais - EnEO, Gramado, RS, 2014.

BRUNSTEIN, J.; COELHO JR., P. J.. Gênero e Diversidade: o jeitinho da construção social da carreira da mulher executiva atuante em um universo profissional de predomínio masculino. In: Encontro de Estudos Organizacionais - EnEO, Porto Alegre, RS, 2006.

CARDOSO, A. L. J.; HANASHIRO, D. M. M.. A Institucionalização da Valorização da Diversidade no Campo Organizacional constituído por Empresas Fornecedoras e Cliente. In: Encontro de Estudos Organizacionais - EnEO, Curitiba, PR, 2012.

COSTA, S. G.; FERREIRA, C. S.. Diversidade e Minorias nos Estudos Organizacionais Brasileiros:

Presenças e Lacunas na Última Década. In:

Encontro de Estudos Organizacionais - EnEO, Porto Alegre, RS, 2006.

DOVAL, J. L. M. ; HARO, D. G. . Ingenuidade e Exclusão: Pessoas Portadoras de Deficiência no Mercado Competitivo. In: Encontro de Estudos Organizacionais - EnEO, Porto Alegre, RS, 2006.

ECCEL, Cláudia Sirangelo; GRISCI, C. L. I..

Trabalho, Gênero e Subjetividade: a Valorização dos Engenheiros em uma Empresa do Setor Petroquímico. In: Encontro Nacional de Estudos Organizacionais - EnEO, Florianópolis, SC, 2010.

FELIPE, M. G. L.; MELO, M. C. O. L.; PINTO, 
R. A.; LOPES, A. L. M.. Empoderamento ou

Violência Simbólica: Percepção de Mulheres

Docentes em Cursos de Engenharia do CEFET-MG.

In: Encontro de Estudos Organizacionais da

ANPAD - EnEO, Gramado, RS, 2014.

FERRAZ, S. F. S.; MAPURUNGA, A. N.

V.; FERRAZ, S. B.. A Inserção Tardia de Mulheres no Mercado de Trabalho. In: Encontro de Estudos Organizacionais da ANPAD - ENEO, Curitiba, PR, 2012.

FERREIRA, Juliene Barbosa; RESENDE, R. C.. O Perfil Profissional das Mulheres nas Cooperativas da Região de Monte Carmelo/ MG. In: Encontro Nacional de Estudos Organizacionais - EnEO, Florianópolis, SC, 2010.

FERREIRA, João Batista; SADOYAMA, Adriana Santos Prado. Educação a distância uma alternativa para a educação profissionalizante, inclusiva e formação continuada: Um estudo bibliométrico. Enciclopédia Biosfera, Goiânia, v.11, n.20, p.347, 2015.

FIGUEIREDO, Marina D.. A Desconstrução do Gênero: Elementos para Pensar Possibilidades Alternativas de Organização Social. In: Encontro de Estudos Organizacionais - EnEO, Florianópolis, SC, 2010.

FONTOURA, Daniela dos Santos; OLIVEIRA, Sidinei Rocha de. A construção social do(s) mercado(s) de trabalho: Espaços de luta de classe, gênero e idade. In: Encontro de Estudos Organizacionais - EnEO, Gramado, RS, 2014.

GASPAR, Marcos A.; KUBO, E. K. M.; LEANDRO, D. de P.; SANTOS, K. da S.; NAGAI, L. H..

Qualidade de Vida no Trabalho para Pessoas com Deficiências: um Estudo Empírico. In: Encontro de Estudos Organizacionais - EnEO, Curitiba, PR, 2012.

HANASHIRO, D. M. M.; GODOY, Arilda Schmidt; CARVALHO, Sueli Galego de . Estudos em Diversidades: Reflexões Teóricas e Evidências Práticas. In: Encontro de Estudos Organizacionais - EnEO, Atibaia, SP, 2004.

IRIGARAY, H. A. R.. Identidades Sexuais Não Hegemônicas: A Inserção dos Travestis e Transexuais no Mundo do Trabalho sob a Ótica
Queer. In: Encontro de Estudos Organizacionais

- EnEO, Florianópolis, SC, 2010.

IRIGARAY, H. A. R.; VERGARA, S. C..

Expatriados no Brasil: diferentes nacionalidades, diferentes percepções. In: Encontro de Estudos

Organizacionais - EnEO, Belo Horizonte, MG, 2008.

Lima, M. P.. Qualificação Profissional de

Trabalhadores com Deficiência: interfaces entre

Educação Profissional e Educação Especial. In:

Encontro de Estudos Organizacionais da

ANPAD - EnEO, Gramado, RS, 2014.

LIMA, T. C. B.; VIEIRA JUNIOR, H. G.; LIMA, D. A.. A socialização organizacional de pessoas com deficiência física. In: Encontro de Estudos Organizacionais da ANPAD - EnEO, Gramado, RS, 2014.

LIMA, L. C.; LUCAS, A. C.. Gestão da Diversidade e Gestão de Pessoas: Implicações para a Área de RH. In: Encontro de Estudos Organizacionais EnEO, 2012, Curitiba, PR, 2012.

LOTH, G. B.; SILVEIRA, Nereida S. P. da. Estudo dos Estereótipos nos Envelhecentes Sofredores de Etarismo. In: Encontro de Estudos Organizacionais - EnEO, Curitiba, PR, 2012.

MACHADO DA SILVA, C. L.; VIEIRA, Sueli

Terezinha . Gênero e práticas gerenciais: um estudo no setor bancário paranaense. In: Encontro de Estudos Organizacionais - EnEO, 2004, Atibaia, SP, 2004.

MACÊDO, K. B. ; MACÊDO, G. N. S. ; CAIXETA, Cássia Maria Moura ; HERNANDEZ, Janete Capel. A exclusão da mulher no processo de sucessão familiar. In: Encontro de Estudos Organizacionais - EnEO, Atibaia, SP, 2004.

MACÊDO, Kátia Barbosa; MACÊDO, Goiacira Nascimento Segurato. A percepção das relações de gênero a partir do discurso de homens e mulheres, no contexto organizacional. In: Encontro de Estudos Organizacionais - EnEO, Atibaia, SP, 2004.

MAGESTE, G. S.; MENDES, E. L.; CAPELLE, M. C. A.. Mulher, Trabalho e Cinema: Representações do trabalho feminino no Cinema Brasileiro. In: Encontro de Estudos Organizacionais - EnEO, Porto Alegre, RS, 2006. 
MATTAR, F. N. Pesquisa de Marketing. 3.ed. São Paulo: Editora Atlas, 2001.

MATOS, F. R. N.; FIGUEIREDO, M. D.; QUEZADO, I.; MESQUITA, R. F.. Homem com H: A norma masculina do empreendedorismo informal nas confecções de jeans de Toritama/PE. In: Encontro Nacional de Estudos Organizacionais - EnEO, Gramado, RS, 2014.

MEDEIROS, Cintia Rodrigues de O.; SILVA, N. C.. Homem de verdade: Apelo a um ideal de masculinidade em propagandas de fast food. In: Encontro Nacional de Estudos Organizacionais - EnEO, Gramado, RS, 2014.

MENDES, Rodrigo Hubner. Desmistificando os impactos da diversidade no desempenho das organizações. In: Encontro de Estudos Organizacionais - EnEO, Atibaia, SP, 2004.

MIRANDA, C. M. S.; SILVEIRA, Amélia; HOELTGEBAUM, M.. Empreendedorismo feminino: características das gestoras em uma instituição de ensino superior. In: Encontro de Estudos Organizacionais - EnEO, Belo Horizonte, MG, 2008.

MOREIRA, L. B; ONUMA, F. M. S.; NAVES, F. L.. Percepções acerca das Relações de Gênero e da Divisão Sexual do Trabalho para Pessoas com Deficiência. In: Encontro de Estudos Organizacionais - EnEO, Florianópolis, SC, 2010.

NASCIMENTO, M. C. R.; TEIXEIRA, J. C.; OLIVEIRA, J. S.. Práticas de Segregação e de Resistência nas Organizações: uma Análise Discursiva sobre os Rolezinhos na cidade de Belo Horizonte/MG. In: Encontro de Estudos Organizacionais da ANPAD - EnEO, Gramado, RS, 2014.

NASCIMENTO, Talita Almeida C.; ROCHADE-OLIVEIRA, Sidinei. Diferenças Geracionais no Setor Público: um estudo numa Instituição de Ensino Superior. In: Encontro de Estudos Organizacionais da ANPAD - EnEO, Gramado, RS, 2014.

NASSIF, Vânia Maria Jorge; ANDREASSI, Tales; TONELLI, M. J.. Mulheres Empreendedoras em Situações de Extrema Dificuldade: Um estudo utilizando a Técnica do Incidente Crítico. In:
Encontro de Estudos Organizacionais da

ANPAD - EnEO, Gramado, RS, 2014.

QUEIROZ, L. G. M.; REGO, M. L.; IRIGARAY, H. A. R.. Project Managers: The impact of psychodemography diversity on the career. In: Encontro de Estudos Organizacionais - EnEO, Gramado, RS, 2014.

REZENDE, M. G.; CARVALHO-FREITAS, M. N.. Inclusão de Pessoas com Deficiência no Trabalho: Como os Profissionais de Recursos Humanos Lidam com Essa Realidade?. In: Encontro de Estudos Organizacionais da ANPAD - EnEO, Gramado, RS, 2014.

ROCHA, V. F. T.; LIMA, T. C. B.; FERRAZ, S. F. S.; FERRAZ, S. B.. Programas de Ressocialização de Egressos do Sistema Prisional e a Gestão de Pessoas: Estudo de Casos Múltiplos em Organizações Cearenses. In: Encontro da Divisão de Estudos Organizacionais da ANPAD - EnEO, Curitiba, PR, 2012.

ROSA, Alexandre Reis ; ALVES, Mario Aquino . Framing Global Negro e Políticas Sociais: O Papel do Ativismo Transnacional nas Lutas AntiRacistas no Brasil. In: Encontro de Estudos Organizacionais - EnEO, Gramado, RS, 2014.

SANTOS, R. A.; GUEVARA, Arnoldo José de Hoyos; AMORIM, Maria Cristina Sanches. Corrupção nas Organizações Privadas: Análise da Percepção Moral segundo Gênero, Idade e Grau de Instrução. In: Encontro de Estudos Organizacionais - EnEO, Florianópolis, SC, 2010.

SIQUEIRA, M. V. S.; ZAULI-FELLOWS, Amanda. Diversidade e Identidade Gay nas Organizações. In: Encontro de Estudos Organizacionais - EnEO, Porto Alegre, RS, 2006.

SIQUEIRA, M. V. S.; PRELORENTZOU, J.

S.. Violência Moral e Pessoas com Deficiência: Constrangimentos e Humilhações no Ambiente de Trabalho. In: Encontro de Estudos Organizacionais - EnEO, Belo Horizonte, MG, 2008.

SILVA, L.B.; RUFINO, Walmir. Abordagens Feministas em Estudos Organizacionais e o Movimento de Mulheres na Paraíba. In: Encontro de Estudos Organizacionais - EnEO, Florianópolis, SC, 2010. 
SILVA, Clóvis L. M. da; VIEIRA, Sueli Terezinha. Gênero e práticas gerenciais: Um estudo no setor bancário paranaense. In: Encontro de Estudos Organizacionais - EnEO, Atibaia, SP, 2004.

SILVA, Luís Guilherme Galeão; ALVES, Mario Aquino. A crítica do conceito de diversidade nas organizações. In: Encontro de Estudos Organizacionais - EnEO, Recife, PE, 2002.

SILVA, K.A.T; CAPPELLE, M. C. A.. Sentidos do Trabalho Apreendidos por Meio de Fatos Marcantes na Trajetória de Mulheres Prostitutas. In: Encontro de Estudos Organizacionais - EnEO, 2014, Gramado, RS, 2014.

SOARES, A.; MORAES, A. F. M.; SOUZA, M. M.

P.. A Dominação Masculina nos Campos Profissional e Pessoal: Um Estudo Qualitativo com MicroEmpresárias de Manaus/AM. In: Encontro de Estudos Organizacionais da ANPAD - EnEO, Curitiba, PR, 2012.

STROBINO, M. R. C.; TEIXEIRA, R. M.. Empreendedorismo Feminino e o Conflito Trabalho-Família: Estudo de Multicasos no Setor da Construção Civil da Cidade de Curitiba. In: Encontro de Estudos Organizacionais - EnEO, Florianópolis, SC, 2010.

TONELLI, M. J.; CEPELLOS, Vanessa; SILVA, Gabriela Toledo. O Envelhecimento e a construção da idade profissional na esfera do trabalho. In:

Encontro de Estudos Organizacionais da ENPAD - EnEO, Gramado, RS, 2014.

TROCCOLI, Ireni Ragueneti, GIMENEZ, Karen; REIS, Patrícia Nunes Costa; FARIA, Patrícia Prado. Comportamento do consumidor: um estudo bibliométrico nos Enanpads 2007-09. São Bernardo do Campo, 2011.

VIEIRA, A.; SOUSA NETO, J. A.; ROSCOE, M. T.. Relações de influência entre dimensões da transgeracionalidade e dimensões da cultura: estudo de casos de empresas familiares. In: Encontro de Estudos Organizacionais - EnEO, Florianópolis, SC, 2010.

ZAMPIER, M. A.; TAKAHASHI, Adriana Roseli Wünch. Intraempreendedorismo Feminino, Competências Empreendedoras e Conflito TrabalhoFamília: Um Estudo de Caso com Professoras de Programas de Mestrado e Doutorado em Administração de Curitiba-PR. In: Encontro de Estudos Organizacionais - EnEO, Florianópolis, SC, 2010. 